\title{
Synthesis and Applications of Nanocontainers and Nanorattles
}

\author{
Sarah-Luise Abram, Philippe Yep, and Katharina M. Fromm
}

\begin{abstract}
Nanorattles and hollow nanocontainers have unique properties related to the presence of a void space inside the shell, which has been shown to improve the properties of materials for e.g. catalysis, drug release, sensor materials or lithium ion batteries. This article summarizes our recent progress in the synthesis of hollow silica, titania and ceria nanorattles and nanocontainers, eventually encapsulating AgNPs as cargo and highlights their potential applications in catalysis and biomedicine.
\end{abstract}

Keywords: Antimicrobial $\cdot$ Catalysis $\cdot \mathrm{SiO}_{2}$ nanorattles $\cdot$ Silver nanoparticles $\cdot \mathrm{TiO}_{2}$ nanocontainers

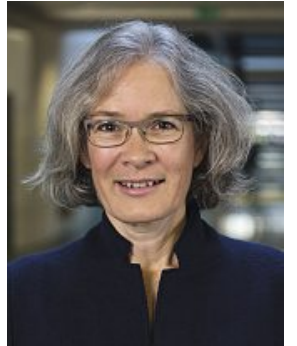

Katharina M. Fromm studied chemistry in Karlsruhe and Strasbourg before receiving a $\mathrm{PhD}$ from the TU Karlsruhe in 1994. She carried out her postdoctoral studies with, among others, Nobel-Prize winner Jean-Marie Lehn in Strasbourg, and did her habilitation at the University of Geneva. In 2003, she became SNSF-Professor at the University of Basel before moving to a full professorship at the University of Fribourg in 2006. She is currently Vice-President of the Research Council of the SNSF, Fellow of the American Chemical Society, elected member of the European Academy of Sciences and recipient of the Prix Jaubert of the University of Geneva in 2018.

\section{Hollow Nano/Micro-structures in Nature}

A hollow nano/micro-structure is defined as a solid structure with a void space inside a distinct shell and nano- or micrometer dimensions. ${ }^{[1]}$ Such structures can be classified according to their overall shape, the number of shells, or the presence of one or several movable cores (see Fig. 1A and B); Core and shell materials can be organic, inorganic, or composites, e.g. polymers, ceramics, metals, metal oxides or other chalcogenides. ${ }^{[2]}$ Nature offers a great variety of such hollow structures exploiting the nano- or microscale dimensions for different purposes. For example, ferritins are large proteins whose structure comprises a hollow cavity used for storage and on demand release of iron (see Fig. 1C). ${ }^{[3]}$ Pollen microcapsules are used by plants to shield their male sperm from harsh environmental conditions (see Fig. 1D). ${ }^{[4]}$ Compartmentalization and hierarchical structuring at the micro- or nanoscale are ubiquitous principles in biology realized in membrane-bound structures such as cells, viral envelopes and capsids or other vesicles. ${ }^{[5]}$ Hence, membrane separation allows the cooperative organization of two otherwise chemically incompatible functionalities as it is e.g. realized for photosystem I and II with the thylakoid membrane which was recently mimicked by polymeric nanocontainers. ${ }^{[6]}$

Natural photonic materials are also based on hierarchical hollow nanostructures: The Edelweiss plant uses hollow nanostructured filaments as UV absorbers, that dissipate the energy and thus protect the plant from the damaging radiation. ${ }^{[7]}$ Another example is the strong iridescence of the hair-like setae of many polychaete

${ }^{*}$ Correspondence: Prof. Dr. K. M. Fromm

E-mail: katharina.fromm@unifr.ch

University of Fribourg, Department of Chemistry, Chemin du Musée 9 ,

$\mathrm{CH}-1700$ Fribourg worms (Fig. 1E) resulting from the periodic arrangement of voids into the lattice of a pseudo-photonic crystal. ${ }^{[8]}$

\section{Benefits and Applications of Nanocontainers and Nanorattles}

Compared to their solid counterparts, hollow nanostructures provide additional properties, which are advantageous for many applications: i) high specific surface area, ii) low density, and iii) high loading capacity for molecular species, gases or nanoparticles. ${ }^{[1]}$ The low density is interesting for their application in fillers, pigments or coatings ${ }^{[9]}$ whereas the large surface area is useful for sensing applications ${ }^{[10]}$ and in catalysis either as the active catalyst ${ }^{[11]}$ or as support material. ${ }^{[12]}$ In nanorattles (NR), the movable core particle is protected from aggregation, coalescence, sintering and the outside chemical environment by the shell, thus preserving the core's catalytic activity. Porosity in the shell allows the diffusion of the reactants to the core while the void provides a confined space for the reaction. The NR architecture thus overcomes the problem of a restricted access to the core's active surface in traditional core shell particles. ${ }^{[12]}$ Moreover, the presence of the void may alter the optical,[13] magnetic, ${ }^{[14]}$ electronic or photocatalytic properties of certain materials. ${ }^{[15]}$ Hollow nanostructures were as well successfully applied in energy storage devices such as Li ion batteries or supercapacitors as their void buffers the huge volume variation during lithiation and delithiation processes ${ }^{[16]}$ and their high surface area results in a large electrolyte-electrode interface with an increased $\mathrm{Li}^{+}$ion flux.[17]

More complicated hierarchical hollow structures show a great potential for the development of multifunctional materials, e.g. in theranostics ${ }^{[18]}$ where imaging agents for diagnosis (fluorescent dyes or particles, but also MRI, ${ }^{[19]}$ ultrasound ${ }^{[20]}$ or photoacoustic imaging ${ }^{[21]}$ contrast agents) are combined with drug delivery or other therapeutic approaches in one product. In this sense, hollow mesoporous silica, ${ }^{[22]}$ polymeric vesicles, ${ }^{[23]}$ and different $\mathrm{NR}^{[12]}$ are loaded with anticancer drugs, ${ }^{[24]}$ ibuprofen, ${ }^{[25]}$ enzymes, ${ }^{[26]}$ or siRNA ${ }^{[27]}$ and are sometimes even modified to achieve a stimuliresponsive drug release activated by temperature, ${ }^{[26]} \mathrm{pH},{ }^{[28]}$ enzymes, ${ }^{[29]}$ or the $\mathrm{K}^{+}$concentration. ${ }^{[30]}$

\section{Synthesis of Nanocontainers and Nanorattles}

The synthesis of hollow nanostructures can be roughly divided into three approaches for the void creation: (1) hard templating, (2) soft templating, and (3) self-templating. ${ }^{11]}$

In the Fromm group, all three approaches were used for the synthesis of silica, titania and ceria nanocontainers (NC) and nanorattles (NR) encapsulating Ag nanoparticles (AgNPs). The 
Fig. 1. Schematic representation of hollow nanostructures with different shapes and hierarchical levels: (A) hollow spheres, ellipsoids, tubes, boxes/cubes, tori or cages. (B) multi-shelled hollow spheres and cubes (cube-in-box), nanorattles/yolk-shell particles with one or multiple cores, wire-in tube structures, and decorated hollow nanospheres. (C) Encapsulation of iron inside the ferritin cage, image reprinted from http://www.chm. bris.ac.uk/motm/ferritin/ferritintutorial_molmonth.html (15.11.2018). (D) Electron micrograph of different pollen and (E) Natural photonic crystals in the spines of Aphrodita and Pherusa (TEM reprinted (adapted) with permission from ref. [8], copyright 2009 American Physical Society, photograph by 'Little Boffin (PeterEdin)' licensed under CC BY-NC-SA 2.0).
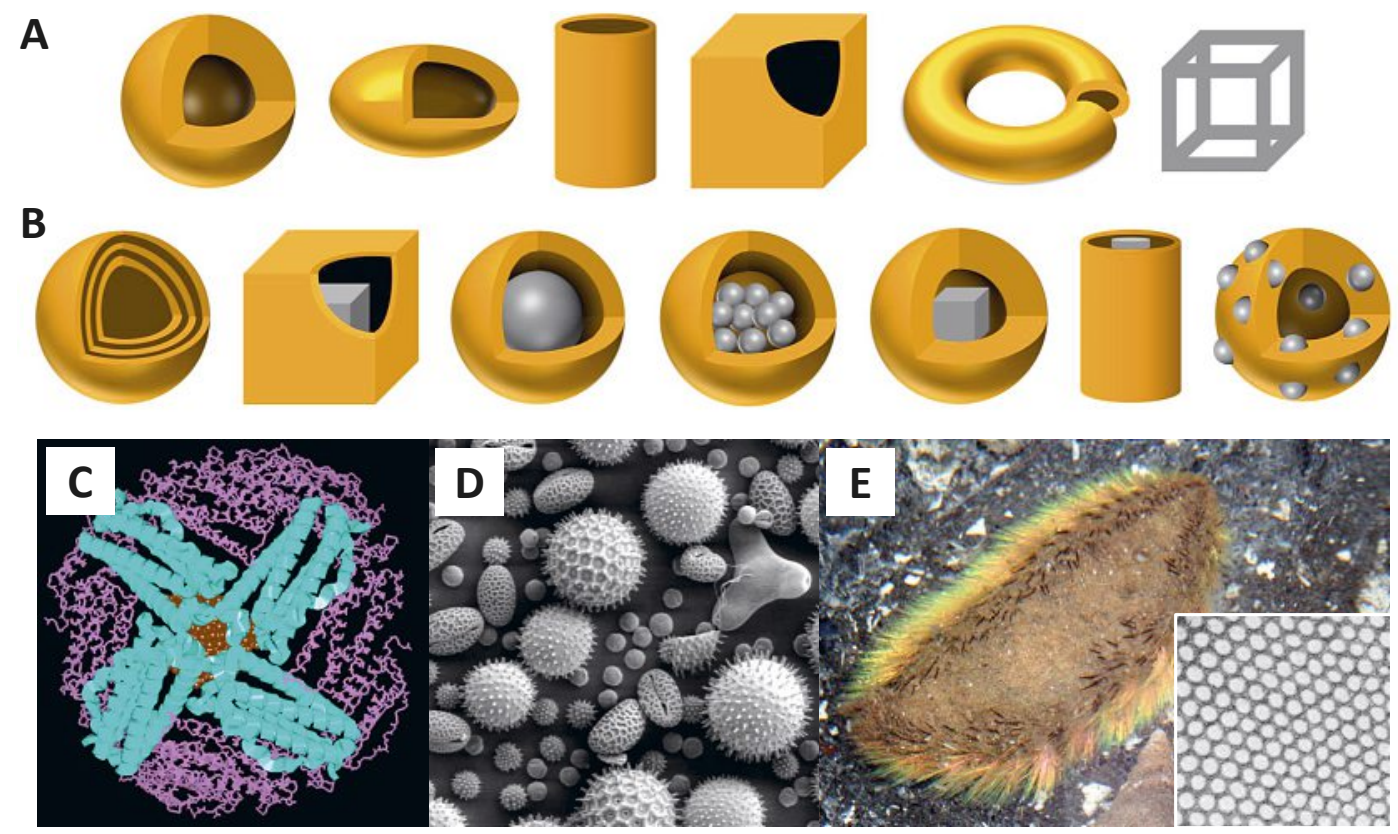

scope of these NC and NR ranges from the improvement of Agbased antimicrobial coatings for medical devices to applications in catalysis for redox reactions, photoelectrochemical water splitting, $\mathrm{CO}_{2}$ reduction or the degradation of dyes. The following paragraphs will provide an overview of some of the synthesized materials and their applications.

\section{$\mathrm{Ag}-\mathrm{CeO}_{2}$ and $\mathrm{Ag}-\mathrm{TiO}_{2} \mathrm{NC}$ by the Hard Template Method}

For any hard template syntheses, the selective heterogeneous precipitation of the shell material onto the template as well as a selective removal strategy for obtaining the void without damaging the shell are both crucial for a homogeneous product. Size and shape of the void depend strongly on the template's size and shape, with the shell thickness being controlled by the coating procedure. Common coating strategies comprise sol-gel methods, polymerizations or hydrothermal reactions on polymer, silica, carbon, ceramic, or metal nanoparticles as typical templates.

Since the first report in 1998 by Caruso et al. on the synthesis of hollow microstructures using layer-by-layer deposition on polystyrene (PS) templates they became a popular template material for a great variety of shell materials as they are readily available in various diameters and easily removed by dissolution in organic solvents or calcination. ${ }^{[1,31]}$ Our group has used anionic $200 \mathrm{~nm}$ PS spheres for the synthesis of a series of $\mathrm{TiO}_{2}$ and $\mathrm{CeO}_{2}$ $\mathrm{NC}$, either with or without the integration of $\mathrm{AgNPs}^{2} \mathrm{Ag}^{+}$into the shell and cavity for antimicrobial activity or the improvement of photocatalytic properties (Fig. 2). ${ }^{[32]}$

Encapsulation of silver salts inside $\mathrm{CeO}_{2} \mathrm{NC}$ resulted in a sustained release of $\mathrm{Ag}^{+}$as antimicrobial active species over a period of several weeks. ${ }^{[32 b]}$ Replacing the salt by AgNPs enabled a further prolongation of the $\mathrm{Ag}^{+}$release to several months, making $\mathrm{Ag}-\mathrm{CeO}_{2} \mathrm{NC}$ promising candidates for long-term infection prevention. The addition of a second shell made from $\mathrm{TiO}_{2}$ restricted the $\mathrm{Ag}^{+}$release even more while still preserving the antimicrobial activity in agar diffusion tests. ${ }^{[32 a]}$ After three months, the remaining $\mathrm{Ag}$ (>90\% of the total initial Ag content) could be released by addition of nitric acid showing the potential for a triggered ondemand release of $\mathrm{Ag}^{+}$from these $\mathrm{Ag}-\mathrm{CeO}_{2} @ \mathrm{TiO}_{2} \mathrm{NC}$, as many bacteria tend to acidify their environment. ${ }^{[33]}$

The same synthetic route was used for $\mathrm{Ag}-\mathrm{TiO}_{2} \mathrm{NC}$ that were tested for the photocatalytic reduction of $\mathrm{CO}_{2}$ to value-added organic molecules. ${ }^{[34]} \mathrm{A}$ complex hierarchical structure has been shown to enhance the photocatalytic performance of $\mathrm{TiO}_{2}$ com-
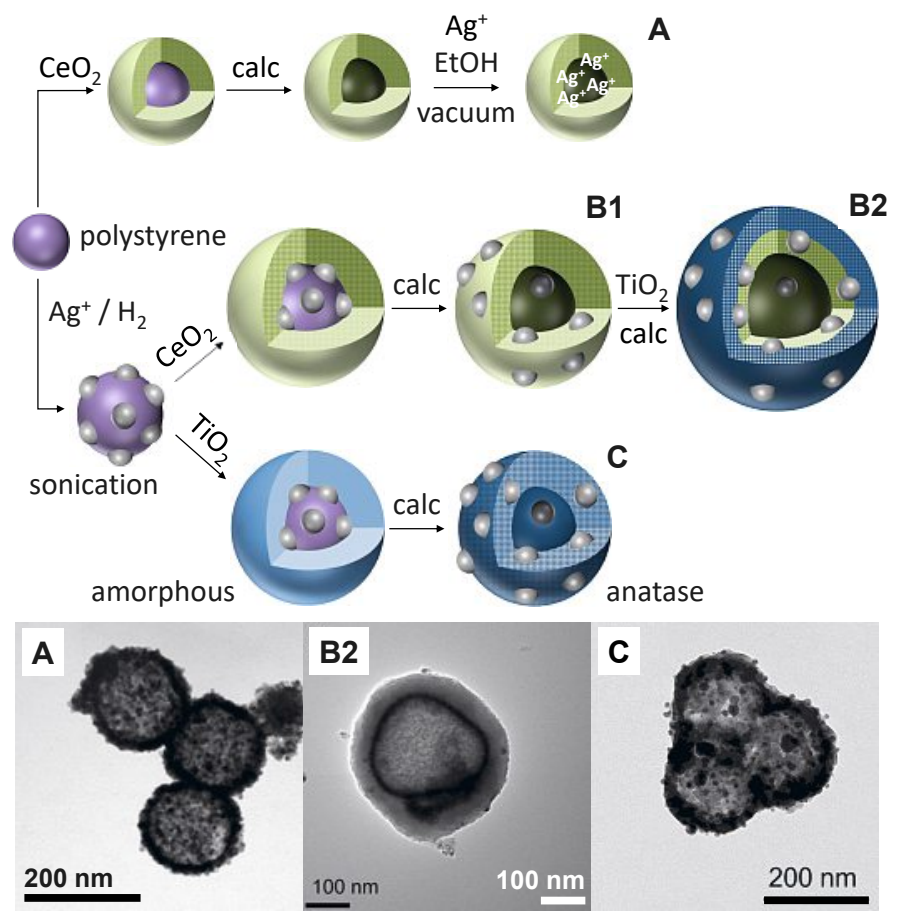

Fig. 2. Scheme of the hard template synthesis of $\mathrm{Ag}^{+}-\mathrm{CeO}_{2}(\mathrm{~A}), \mathrm{Ag}-\mathrm{CeO}_{2}$ (B1), Ag- $\mathrm{CeO}_{2} @ \mathrm{TiO}_{2}$ (B2), and $\mathrm{Ag}-\mathrm{TiO}_{2}$ (C) nanocontainers by sol-gel coating of $200 \mathrm{~nm}$ PS spheres (violet) with $\mathrm{CeO}_{2}$ (green) and $\mathrm{TiO}_{2}$ (blue) layers and subsequent template removal by calcination and their TEM images. Micrographs (A), (B2) and (C) taken from ref. [32b], ref. [32a] and ref. [34] respectively.

pared to common nanoparticles or bulk materials. ${ }^{[35]}$ Moreover, integrated AgNPs could act as electron scavengers and thus lower the electron-hole recombination rate which was shown to shift the product mixture to more electron-demanding products at the expense of $\mathrm{CO}$ (i.e. methane requiring $8 \mathrm{e}^{-}$instead of $2 \mathrm{e}^{-}$for $\mathrm{CO}$ ). ${ }^{[36]}$ Besides the photoreduction of $\mathrm{CO}_{2}, \mathrm{TiO}_{2}$ nanomaterials are used for photoelectrochemical water splitting as second contribution to the quest for alternative energy sources and storage. ${ }^{[37]}$ The NC morphology as well as doping with AgNPs could be interesting ways to increase the photocatalytic efficiency by shifting the absorption to the visible range. ${ }^{[38]}$

As a drawback, the above-described $\mathrm{Ag}-\mathrm{CeO}_{2}$ and $\mathrm{Ag}-\mathrm{TiO}_{2}$ $\mathrm{NC}$ lacked monodispersity as the integration of AgNPs into the 


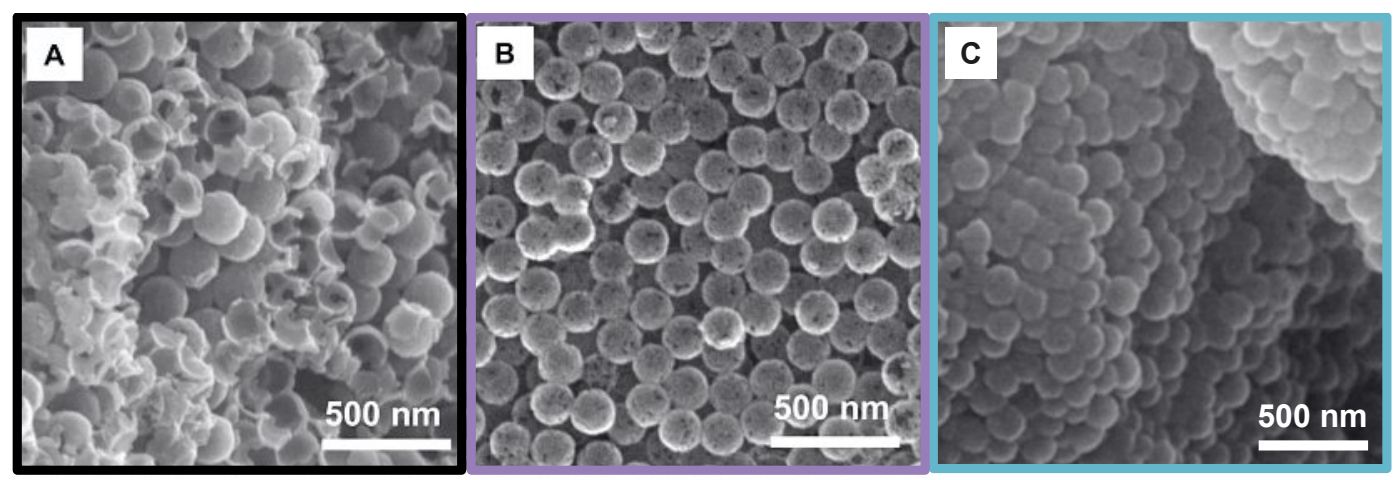

Fig. 3. Scanning electron micrographs of anatase $\mathrm{TiO}_{2} \mathrm{NC}$ by hard template synthesis with $(A)$ direct calcination or (B) Soxhlet extraction prior to calcination and (C) with increased wall thickness. (D) Photodegradation of MB by the mentioned anatase $\mathrm{TiO}_{2} \mathrm{NC}$ and $(\mathrm{E})$ their pseudo first order kinetics. Reprinted from ref. [32d].

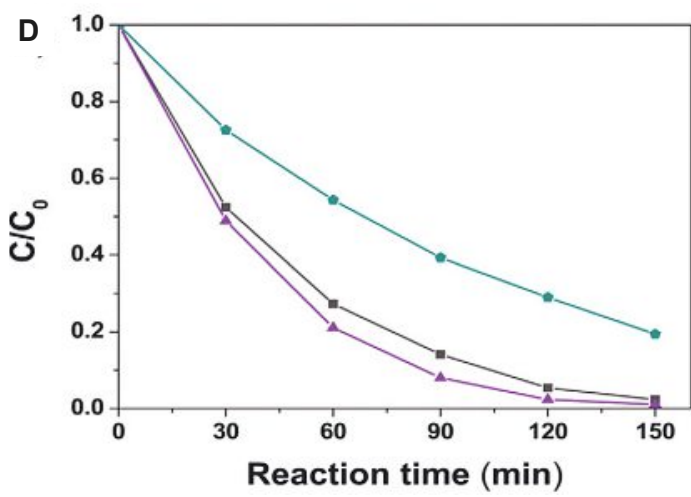

PS templates by sonication led to coalescence. Moreover, the removal of the PS template by calcination was found to damage the $\mathrm{TiO}_{2}$ shell (Fig. 3A). ${ }^{[32 \mathrm{~d}]}$ Instead, dissolution of the PS via a mild Soxhlet extraction with chloroform kept the shells intact even after a subsequent calcination (Fig. 3B). ${ }^{[32 \mathrm{~d}]}$ The resulting monodisperse $200 \mathrm{~nm}$ anatase $\mathrm{TiO}_{2} \mathrm{NC}$ were used for the photocatalytic degradation of recalcitrant dyes. The photoactivity depended on the shell morphology: broken, holey shells resulting from direct thermal template degradation showed lower activity than intact $\mathrm{TiO}_{2} \mathrm{NC}$ obtained from Soxhlet extraction and subsequent calcination (see Fig. 3D and E). An increase of shell thickness drastically reduced the catalytic activity as well.

Reduction of $\mathrm{Ag}^{+}$by $\mathrm{NaBH}_{4}$ in presence of the PS template and subsequent $\mathrm{TiO}_{2}$ coating resulted in monodisperse $200 \mathrm{~nm}$ $\mathrm{Ag}-\mathrm{TiO}_{2} \mathrm{NC}$ with intact shells before and after calcination. ${ }^{[32 \mathrm{c}]}$ Besides their application in photoelectrochemical water splitting, ${ }^{[38]}$ the $\mathrm{Ag}-\mathrm{TiO}_{2} \mathrm{NC}$ were also evaluated for their potential as antimicrobial active material.[32c] Amorphous as well as anatase $\mathrm{TiO}_{2} \mathrm{NC}$ with 2 or $8 \mathrm{wt} \% \mathrm{Ag}$ loading were studied for their antimicrobial, immunological and cytotoxic profiles towards murine macrophages and fibroblasts in order to ensure that an eventual antibacterial coating based on these particles would not only be efficient but also biocompatible. Even if the particles are firmly attached to an implant surface, they might detach and thus uptake by immune cells is likely, calling for the investigation of their immunological impact. We found that all studied particles did not induce any immune response and the active uptake of significant amounts, proven by flow cytometry, confocal microscopy, as well as electron microscopy, did not impact the macrophages' viability. A long-term sustained release of $\mathrm{Ag}^{+}$could be measured for all the different $\mathrm{Ag}-\mathrm{TiO}_{2} \mathrm{NC}$, being highest for anatase $\mathrm{TiO}_{2} \mathrm{NC}$ with 8 $\mathrm{wt} \% \mathrm{Ag}$. In line with that, they provided the highest antimicrobial activity among all samples, being even bactericidal to methicillin resistant $S$. aureus, while showing the same cytocompatibility as the other particles.

\section{Ag@SiO 2 NR Using a Microemulsion Template}

Soft templates with flexible shapes are the second possibility for the generation of voids inside nanomaterials. The shells are deposited via sol-gel routes, hydrothermal reactions, emulsion polymerizations or other precipitation reactions at the interface of the soft templates. Emulsions can be especially useful for the synthesis of rattle-type hollow nanostructures as the core particles can be encapsulated or synthesized inside the micelle. In the Fromm group, $\mathrm{Ag} @ \mathrm{SiO}_{2} \mathrm{NR}$ were prepared in a reverse microemulsion system. ${ }^{[39]}$ The synthesis exploits the different solubility of two silica precursors to induce a structural difference within the silica shell, which allows for a selective etching of the inner part. The micelle restricts the overall particle size. In the first step, hydrazine reduces $\mathrm{Ag}^{+}$in the aqueous phase to form the Ag cores (Fig. 4A). The shells are then hydrolyzed from tetraethyl orthosilicate (TEOS) and (3-aminopropyl)trimethoxysilane (APTMS). TEOS is better soluble in the cyclohexane phase, whereas APTMS condenses in the aqueous phase around the Ag core. The void between the Ag and the silica shell is formed by short washing in warm water which selectively etches the less 'dense' silica network close to the Ag core derived from APTMS. Variation of the $\mathrm{Ag}^{+}$concentration tunes the ratio of filled $\mathrm{Ag} @ \mathrm{SiO}_{2} \mathrm{NR}$ to empty silica $\mathrm{NC}$ and thus the materials' overall Ag loading (e.g. 3, 13 and $23 \mathrm{wt} \%)$. ${ }^{40]}$ In dynamic release experiments, a continuous $\mathrm{Ag}^{+}$release was observed (enhanced with higher Ag loading), leading to better antimicrobial activity of the $\mathrm{Ag} @ \mathrm{SiO}_{2} \mathrm{NR}$ with higher $\mathrm{Ag}$ content. The particles did not induce inflammation, hemolysis nor did they affect the viability or metabolism of dendritic cells at concentrations that had strong antibacterial effects. ${ }^{[40]}$ The Ag@ $\mathrm{SiO}_{2} \mathrm{NR}$ provided as well good catalytic activity that was studied with the reduction of methylene blue (MB) to its colorless leuco form by $\mathrm{NaBH}_{4}$ as model reaction. [39]

\section{Self-templating Strategy for ${\mathrm{Ag} @ \mathrm{SiO}_{2} \mathrm{NR}}$}

Self-templating strategies are usually less complex than hard or soft templating as they require fewer synthesis steps. They are reported to have an increased potential for reproducibility, successful scale-up and lower production costs. ${ }^{[9]}$ Moreover, they avoid the calcination step frequently used for template removal, which is not compatible with temperature-sensitive shell materials, altering shell morphology in an undesired way. ${ }^{[9,42]}$ Surface 

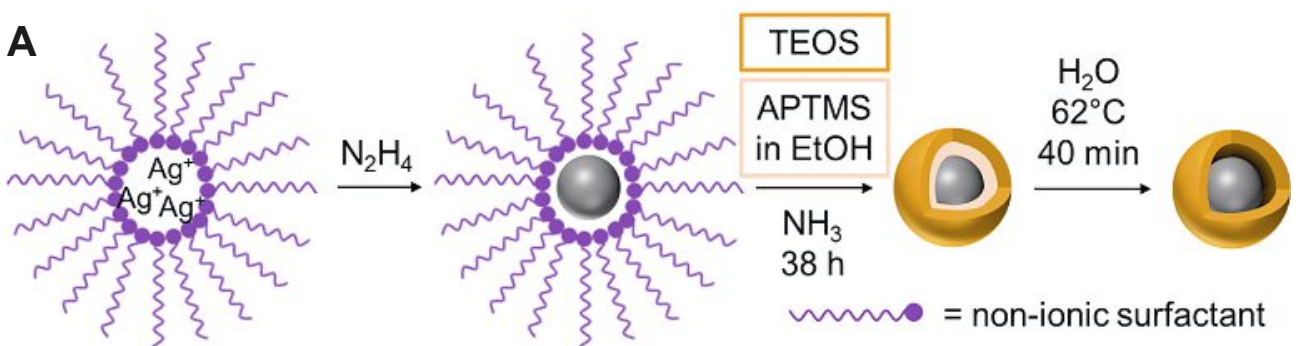

C

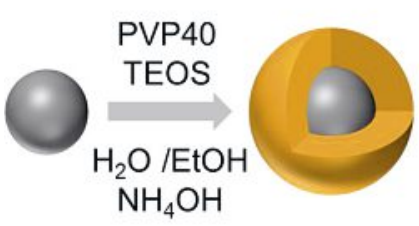

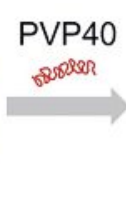
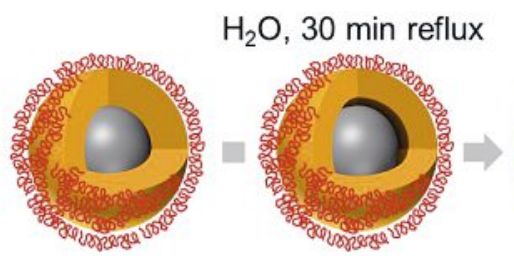

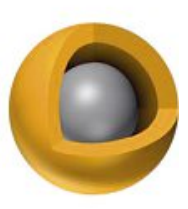

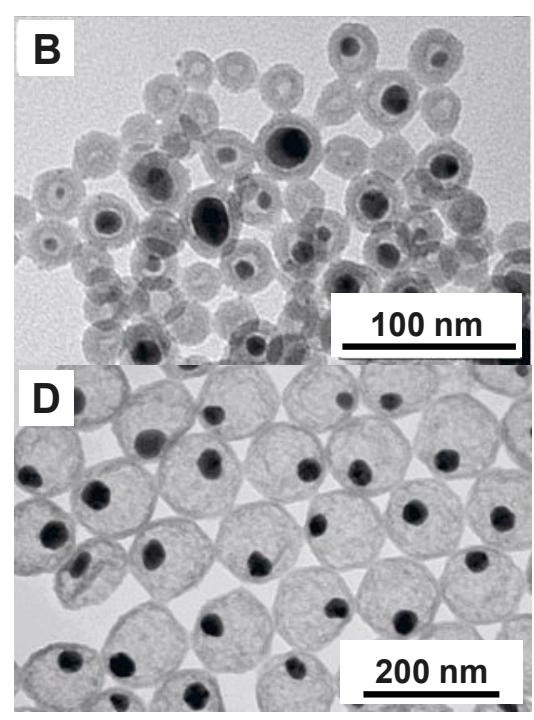

Fig. 4. (A) Microemulsion synthesis of $25 \mathrm{~nm} \mathrm{Ag@SiO}{ }_{2}$ nanorattles and (B) their electron micrograph. Reprinted from ref. [39]. (C) Surface protected etching as self-templating approach to $100 \mathrm{~nm} \mathrm{Ag@SiO}{ }_{2}$ nanorattles and (D) their electron micrograph.[41]

protected etching, as one example of self-templating techniques, enhances the relative stability of a nanoparticle's surface, which enables the selective removal of the interior. ${ }^{[9,43]}$ In order to realize $\mathrm{Ag} @ \mathrm{SiO}_{2} \mathrm{NR}$, solid $\mathrm{Ag} @ \mathrm{SiO}_{2}$ core shell (CS) particles were synthesized and coated with a layer of polyvinylpyrrolidone (PVP40) that coordinates strongly with its carbonyl groups to hydroxyl groups on the silica surface via hydrogen bonding. ${ }^{[44]}$ The polymer chains are too large to diffuse inside the shell and thus they protect the particle's outer surface during the etching process. Water is small enough to penetrate the shell and can be used as a mild etching agent on Stöber derived silica, which shows increased water solubility at elevated temperatures due to incomplete polycondensation of the alkoxide precursors. ${ }^{[45]}$ Our synthesis resulted in very homogeneous Ag@ $\mathrm{SiO}, \mathrm{NR}$ with a distinctive void between the Ag core and the thin silica shell, while avoiding empty silica NC. ${ }^{[41]}$ The protective role of the silica shell was clearly demonstrated again in the catalytic reduction of MB. Contrary to AgNP isolated before the silica coating, $\mathrm{Ag} @ \mathrm{SiO}_{2} \mathrm{CS}$ and NR led to a fast initial decrease of the MB absorption band and its complete disappearance within $30 \mathrm{~min}$. Furthermore, the Ag@ $\mathrm{SiO}, \mathrm{CS}$ and NR showed excellent bactericidal properties, even against methicillin resistant $S$. aureus. ${ }^{[41]}$ A first promising cytocompatibility evaluation using murine fibroblasts together with the easy way of functionalization using silica precursors with one non-hydrolysable side chain will allow the exploitation of the high antimicrobial efficacy for nanobiomaterials.

\section{Conclusion}

Overall, all three synthetic strategies have proven to be useful for the preparation of hollow nanostructured materials, especially for realizing different sizes with hard templates for $\geq 200 \mathrm{~nm}$, self-templating for about $100 \mathrm{~nm}$ and the microemulsion for the smallest nanocontainers of $25 \mathrm{~nm}$. While the microemulsion soft template required precise control of the reaction conditions for reproduction and selectivity of the silica nucleation on the $\mathrm{Ag}$ cores was hardly achieved, the self-templating approach allowed an easy and fast access to a homogenous encapsulation of the $\mathrm{Ag}$ cores. But, in contrast to the hard template approach, both syntheses are rather limited in their yield and batch scale. With regard to the biological evaluation of the Ag-containing particles anatase $\mathrm{Ag}-\mathrm{TiO}_{2} \mathrm{NC}$ and the surface protected etching derived $\mathrm{Ag} @ \mathrm{SiO}_{2}$ NR were identified as the most promising candidates for introduction into biomaterials, e.g. into polymer composites or as coatings on implant surfaces.

\section{Acknowledgements}

The authors would like to thank the University of Fribourg and the Swiss National Science Foundation, in particular the National Center of Competence in Research 'Bio-Inspired Materials' for the generous funding of the project.

Received: Nov. 15, 2018

[1] X. Wang, J. Feng, Y. Bai, Q. Zhang, Y. Yin, Chem. Rev. 2016, 116, 10983.

[2] M. Priebe, K. M. Fromm, Chem. Eur. J. 2015, 21, 3854.

[3] P. Arosio, R. Ingrassia, P. Cavadini, Biochim. Biophys. Acta 2009, 1790, 589

[4] R. C. Mundargi, M. G. Potroz, S. Park, H. Shirahama, J. H. Lee, J. Seo, N. J. Cho, Small 2016, 12, 1167.

[5] T. Trantidou, M. Friddin, Y. Elani, N. J. Brooks, R. V. Law, J. M. Seddon, O. Ces, ACS Nano 2017, 11, 6549.

[6] J. Sun, J. Zhang, M. Zhang, M. Antonietti, X. Fu, X. Wang, Nat. Commun. 2012, 3.

[7] J. P. Vigneron, M. Rassart, Z. Vértesy, K. Kertész, M. Sarrazin, L. P. Biró, D Ertz, V. Lousse, Phys. Rev. E 2005, 71, 011906.

[8] T. M. Trzeciak, P. Vukusic, Phys. Rev. E 2009, 80, 061908.

[9] Q. Zhang, W. Wang, J. Goebl, Y. Yin, Nano Today 2009, 4, 494.

[10] J.-H. Lee, Sens. Actuator B Chem. 2009, 140, 319.

[11] C. W. Yen, M. A. Mahmoud, M. A. El-Sayed, J. Phys. Chem. A 2009, 113 4340 .

[12] J. Liu, S. Z. Qiao, J. S. Chen, X. W. Lou, X. Xing, G. Q. Lu, Chem. Commun. 2011, 47, 12578 .

[13] a) N. Halas, MRS Bulletin 2011, 30, 362; b) M. Retsch, M. Schmelzeisen, H.-J. Butt, E. L. Thomas, Nano Lett. 2011, 11, 1389; c) L. Zhang, H. Wang, ACS Nano 2011, 5, 3257.

[14] a) J. Dinesh, M. Uzma, M. Pranab, S. Athinarayanan, E. Muthusamy, Angew. Chem. Int. Ed. 2008, 120, 7799; b) Y. Wang, Q. Zhu, H. Zhang, J. Mater. Chem. 2006, 16, 1212.

[15] C. C. Nguyen, N. N. Vu, T.-O. Do, J. Mater. Chem., A 2015, 3, 18345.

[16] a) X. W. Lou, L. A. Archer, Z. Yang, Adv. Mater. 2008, 20, 3987; b) S. Laifa, Y. Le, Y. Xin-Yao, Z. Xiaogang, L. X. Wen, Angew. Chem. Int. Ed. 2015, 54, 1868.

[17] W. Zhiyu, Z. Liang, L. X. Wen, Adv. Mater. 2012, 24, 1903.

[18] a) S. S. Kelkar, T. M. Reineke, Bioconjug. Chem. 2011, 22, 1879; b) J. Xie, S. Lee, X. Chen, Adv. Drug Delivery Rev. 2010, 62, 1064.

[19] a) Y. Chen, H. Chen, D. Zeng, Y. Tian, F. Chen, J. Feng, J. Shi, ACS Nano 2010, 4, 6001; b) W. Huixia, Z. Shengjian, Z. Jiamin, L. Gang, S. Jianlin, Z. Lingxia, C. Xiangzhi, R. Meiling, H. Qianjun, B. Wenbo, Adv. Funct. Mater. 2011, 21, 1850 .

[20] H. Hu, H. Zhou, J. Du, Z. Wang, L. An, H. Yang, F. Li, H. Wu, S. Yang, J. Mater. Chem. 2011, 21, 6576.

[21] X. Yang, S. E. Skrabalak, Z.-Y. Li, Y. Xia, L. V. Wang, Nano Lett. 2007, 7, 3798.

[22] a) R. K. Singh, T.-H. Kim, C. Mahapatra, K. D. Patel, H.-W. Kim, Langmuir 2015, 31, 11344; b) X. Fang, X. Zhao, W. Fang, C. Chen, N. Zheng, Nanoscale 2013, 5, 2205.

[23] P. Tanner, P. Baumann, R. Enea, O. Onaca, C. Palivan, W. Meier, Acc. Chem. Res. 2011, 44, 1039. 
[24] Y. Hu, X. T. Zheng, J. S. Chen, M. Zhou, C. M. Li, X. W. Lou, J. Mater. Chem. 2011, 21, 8052.

[25] H. Jiu, W. Jia, L. Zhang, C. Huang, H. Jiao, J. Chang, J. Porous Mat. 2015, 22, 1511 .

[26] E. Yu, I. Galiana, R. Martínez-Máñez, P. Stroeve, M. D. Marcos, E. Aznar, F. Sancenón, J. R. Murguía, P. Amorós, Colloids Surf., B 2015, 135, 652.

[27] a) K. H. Bae, K. Lee, C. Kim, T. G. Park, Biomaterials 2011, 32, 176; b) M. Xing, Z. Yun, N. K. Woei, Z. Yanli, Chem. Eur. J. 2013, 19, 15593.

[28] a) Q. Wang, X. Huang, Y. Long, X. Wang, H. Zhang, R. Zhu, L. Liang, P. Teng, H. Zheng, Carbon 2013, 59, 192; b) C. Yu, X. Pengfei, W. Meiying, M. Qingshuo, C. Hangrong, S. Zhu, W. Jin, Z. Lingxia, L. Yaping, S. Jianlin, Adv. Mater. 2014, 26, 4294.

[29] K. Patel, S. Angelos, W. R. Dichtel, A. Coskun, Y.-W. Yang, J. I. Zink, J. F. Stoddart, J. Am. Chem. Soc. 2008, 130, 2382.

[30] Z. Zhang, F. Wang, Y. S. Sohn, R. Nechushtai, I. Willner, Adv. Funct. Mater. 2014, 24, 5662.

[31] F. Caruso, R. A. Caruso, H. Möhwald, Science 1998, 282, 1111.

[32] a) J. Gagnon, M. J. D. Clift, D. Vanhecke, I. E. Widnersson, S. L. Abram, A. Petri-Fink, R. A. Caruso, B. Rothen-Rutishauser, K. M. Fromm, J. Mater. Chem., B 2016, 4, 1166; b) J. Gagnon, M. J. D. Clift, D. Vanhecke, D. A. Kuhn, P. Weber, A. Petri-Fink, B. Rothen-Rutishauser, K. M. Fromm, J. Mater. Chem., B 2015, 3, 1760; c) N. Hérault, J. Wagner, S. L. Abram, L. Horvàth, J. Widmer, C. Bourquin, K. M. Fromm, Nanomedicine: NBM 2019, submitted; d) N. Hérault, K. M. Fromm, Helv. Chim. Acta 2017, 100, e1700014.
[33] L. Zhang, F. Su, X. Kong, F. Lee, K. Day, W. Gao, M. E. Vecera, J. M. Sohr, S. Buizer, Y. Tian, D. R. Meldrum, RSC Adv. 2016, 6, 46134.

[34] N. Hérault, J. Gagnon, P. Reñones, F. Harvey, F. Fresno, D. Chen, R. A. Caruso, V. A. de la Peña O’Shea, K. M. Fromm, manuscript under preparation, 2019.

[35] D. Chen, X. Zhang, A. F. Lee, J. Mater. Chem. A 2015, 3, 14487.

[36] L. Collado, P. Jana, B. Sierra, J. M. Coronado, P. Pizarro, D. P. Serrano, V. A de la Peña O'Shea, Chem. Eng. J. 2013, 224, 128.

[37] Y. Ma, X. Wang, Y. Jia, X. Chen, H. Han, C. Li, Chem. Rev. 2014, 114, 9987.

[38] N. Hérault, V. Kaliginedi, P. Moreno, P. Broekmann, K. M. Fromm, manuscript under preparation, 2019.

[39] M. Priebe, K. M. Fromm, Part. Part. Syst. Char. 2014, 31, 645.

[40] M. Priebe, J. Widmer, N. Suhartha Löwa, S.-L. Abram, I. Mottas, A.K. Woischnig, P. S. Brunetto, N. Khanna, C. Bourquin, K. M. Fromm, Nanomedicine: NBM 2017, 13, 11

[41] S.-L. Abram, K. M. Fromm, manuscript under preparation, 2019.

[42] P. M. Ajayan, O. Stephan, P. Redlich, C. Colliex, Nature 1995, 375, 564

[43] Q. Zhang, T. Zhang, J. Ge, Y. Yin, Nano Lett. 2008, 8, 2867.

[44] a) M. A. Cohen Stuart, G. J. Fleer, B. H. Bijsterbosch, J. Colloid Interface Sci. 1982, 90, 310; b) M. Pattanaik, S. K. Bhaumik, Mater. Lett. 2000, 44, 352.

[45] a) L. L. Hench, J. K. West, Chem. Rev. 1990, 90, 33; b) Y. Hu, Q. Zhang, J. Goebl, T. Zhang, Y. Yin, Phys. Chem. Chem. Phys. 2010, 12, 11836. 